
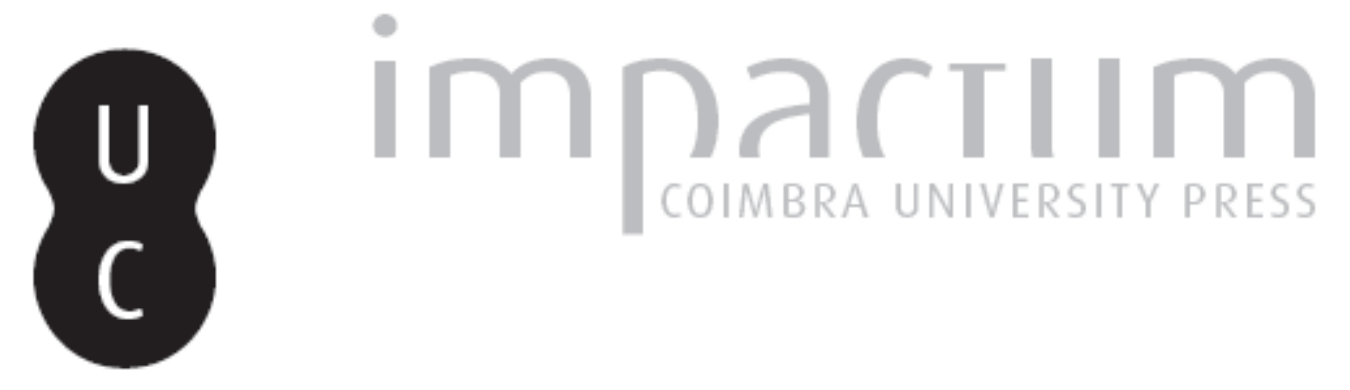

\title{
O território dos Paesuri e as suas principais povoações
}

\section{Autor(es): $\quad$ Alarcão, Jorge de}

Publicado por: Faculdade de Letras da Universidade de Coimbra

URL persistente:

URI:http://hdl.handle.net/10316.2/37810

DOI:

DOI:http://dx.doi.org/10.14195/1647-8657_44_4

Accessed : $\quad$ 26-Apr-2023 11:14:56

A navegação consulta e descarregamento dos títulos inseridos nas Bibliotecas Digitais UC Digitalis, UC Pombalina e UC Impactum, pressupõem a aceitação plena e sem reservas dos Termos e Condições de Uso destas Bibliotecas Digitais, disponíveis em https://digitalis.uc.pt/pt-pt/termos.

Conforme exposto nos referidos Termos e Condições de Uso, o descarregamento de títulos de acesso restrito requer uma licença válida de autorização devendo o utilizador aceder ao(s) documento(s) a partir de um endereço de IP da instituição detentora da supramencionada licença.

Ao utilizador é apenas permitido o descarregamento para uso pessoal, pelo que o emprego do(s) título(s) descarregado(s) para outro fim, designadamente comercial, carece de autorização do respetivo autor ou editor da obra.

Na medida em que todas as obras da UC Digitalis se encontram protegidas pelo Código do Direito de Autor e Direitos Conexos e demais legislação aplicável, toda a cópia, parcial ou total, deste documento, nos casos em que é legalmente admitida, deverá conter ou fazer-se acompanhar por este aviso.

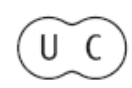




\section{CONIMBRIGA}

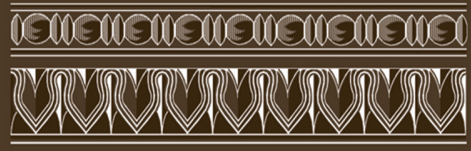

INSTITUTO DE ARQUEOLOGIA

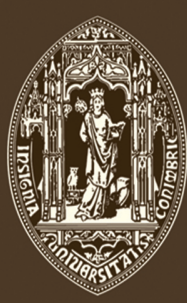

VOLUME XLIV • 2005

FACULDADE DE LETRAS UNIVERSIDADE DE COIMBRA 
JoRGE DE ALARCÃo

Professor catedrático aposentado da Faculdade de Letras de Coimbra

\section{O TERRITÓRIO DOS PAESVRI E AS SUAS PRINCIPAIS POVOAÇÕES} "Conimbriga" XLIV (2005) p. 147-171

RESUmo: Apresenta-se uma proposta de localização dos Paesuri, que são referidos por Plínio e se acham mencionados na inscrição da ponte de Alcântara, CIL II 760. Sugerem-se os limites do território da civitas e identificam-se alguns lugares que, nesse território, parecem ter sido mais importantes, designadamente o de Cárquere.

AbSTRACT: There is a reference in PLINY, IV, 35, 113 to a people of Lusitania called Paesuri. The name of the civitas is present in the famous inscription of the Roman bridge of Alcantara, CIL II 760. The location of the Paesuri and the boundaries of their territory are here discussed. Some more important sites in the territory are identified. 
(Página deixada propositadamente em branco) 


\section{O TERRITÓRIO DOS PAESVRI E AS SUAS PRINCIPAIS POVOAÇÕES}

Plínio, IV, 35, 113 menciona os populi e oppida do extremo noroeste da província da Lusitânia:

A Durio Lusitania incipit. Turduli Veteres, Paesuri, flumen Vagia, oppidum Talabriga, oppidum et flumen Aeminium...

O facto de Plínio mencionar populi (ou apresentar etnónimos) até ao rio Vouga e, a partir deste, citar os oppida que foram capitais de civitates deve tomar-se como índice de diferenças de complexidade sócio-política e cultural, com raízes no período pré-romano. O rio Vouga é, aliás, considerado por Armando Coelho como limite meridional, do lado do Atlântico, da sua "cultura castreja" (SILVA, 1986: 17).

Os Turduli Veteres, também referidos por Pompónio Mela, III, 1, 8, devem situar-se imediatamente a sul do rio Douro e do lado do mar. As tesserae hospitales do Monte Murado ou Castro da Senhora da Saúde (Vila Nova de Gaia), publicadas por Armando Coelho (SiLvA, 1983), confirmam essa localização.

Pelo território dos Turduli Veteres corria a via de Olisipo a Bracara Augusta. A Langobriga que o Itinerário de Antonino situa entre Talabriga e Cale parece dever identificar-se com o Monte de Santa Maria em Fiães da Feira. É possível que este lugar, onde se fizeram escavações todavia não muito extensas (AlmEIDA e SANTOS, 1972 e 1973), corresponda à capital dos Turduli Veteres. Não deve, porém, considerar-se segura essa identificação: Langobriga poderia ser aglomerado urbano secundário e a capital político-administrativa da civitas romana podia ficar noutro sítio (MANTAS, 1996: 640-645), eventualmente distante da estrada principal. Se não ficava em Langobriga mas, ainda assim, no percurso da estrada romana, por que razão o Itinerário de Antonino não a teria mencionado? 
Para além das tesserae do Monte Murado, temos um outro testemunho epigráfico dos Turduli Veteres: uma inscrição achada em Cória, que regista um Quadratus, Mantaif(ilius), Turdulus Vetus (ARMSTEAD, 1975: 174).

Um terminus augustalis encontrado em Ul (Oliveira de Azeméis), mas sem menção dos povos demarcados (AlmEIDA, 1953), indicaria a fronteira entre os Turduli Veteres (a norte) e a civitas de Talabriga (a sul) (AlARCÃO, 2004a: 327-328).

Se, a sudeste, a serra de Arestal poderia marcar a fronteira dos Turduli Veteres, a delimitação do territorium deste povo, a oriente, é mais difícil de precisar, pois não se acha barreira física natural: o rio Arda, o Alarda dos documentos medievais, seria a linha que demarcaria Turduli Veteres, de Paesuri? Estes últimos, mencionados por Plínio no passo anteriormente transcrito e referidos na inscrição da ponte de Alcântara, CIL II 760, achavam-se provavelmente a oriente dos primeiros.

Mais a oriente ainda, estariam os Coilarni. O terminus augustalis de Goujoim (Armamar), provavelmente do tempo de Cláudio, menciona os Coilarni e os Arabrigenses (VAZ, 1979; SILVA, 1985: 222-224; LE RouX, 1994: 40-41).

Temos hesitado na localização da fronteira entre os Paesuri e os Coilarni e na integração do importante povoado de Cárquere (Resende) no território de uns ou outros (ALARCÃO, 2000: 166). Ora entre Lamego e Cárquere avulta um espinhaço da serra de Montemuro em cujas vertentes se situam Penajóia, Barrô e S. Martinho de Mouros. Neste último local ou, mais exactamente, em Mogueira, fica situado um castro e, junto dele, um santuário rupestre (MAnTAS, 1984; Colmenero, 1993: 89-91; Silva e VAz, 2001). Talvez o limite entre Paesuri e Coilarni passasse por este espinhaço da serra de Montemuro. Estaria aqui colocado, no horizonte deste monte, o terminus augustalis de Cláudio que hoje se encontra na igreja de S. Pedro de Balsemão (CIL II 6199; VAZ, 1982: 264-265)? O terminus augustalis, infelizmente, não menciona os "povos" demarcados.

S. Martinho de Mouros seria local importante ainda (ou de novo?) nos meados do séc. XI, pois se menciona na Crónica Geral de Espanha de 1344. Diz o cronista, depois de ter referido a conquista de Lamego por Fernando Magno: "E, depois que esto ouve feito e todo assessegado, foy sobre o castelo de Sam Martinho, que jaz sobrello ryo de Malva, e tomouho logo e foy cercar Tarouca e logo a entrou" (CINTRA, 1961: III, 312). 
A ordem por que a crónica enuncia as conquistas de Fernando Magno (Seia, Gouveia, Viseu, Lamego, S. Martinho, Tarouca) talvez se possa considerar indiciadora de velhas estradas romanas: uma via por Castro Daire ligaria Viseu a Lamego; outra poria Lamego em comunicação com Cinfães e Castelo de Paiva; uma terceira ligaria Lamego a Tarouca e continuaria na direcção de Moimenta da Beira e Sernancelhe ou Penedono.

Parece-nos que os Coilarni teriam sua capital em Lamego. A cidade foi sede episcopal na época suévica e a "diocese" terá sido distraída da de Viseu entre 561 e 572 (DAVID, 1947: 69). E se é certo que imediatamente a norte do Douro temos a "diocese" de Magnetum estabelecida em lugar secundário da civitas de Tongobriga, enquanto a cidade capital foi simples "paróquia" dessa sede (DAVID, 1947: 68; DiAs, 1997), talvez Lamecum não tenha sido, ao contrário do que sugeriu João L. Inês Vaz (1988-1994: 146), simples lugar secundário de uns Coilarni que integrariam as duas áreas de Lamego e Cárquere.

Da possível extrema que assinalámos, o território dos Paesuri viria, por Cárquere, S. Cristóvão de Nogueira, Tarouquela e Santa Maria de Sardoura, até ao rio Arda. Este não tem curso muito significativo mas poderá ter sido, noutro tempo, uma linha de penetração mais importante, quando se subia o rio Douro de barco e, de Pedorido, se alcançava, pelo vale do Arda, a área de Arouca.

As imediações de Castelo de Paiva parecem ter constituído uma zona com alguma importância, quer na época proto-histórica, quer no período romano. Na primeira, avultaria aí o castro de Santa Maria de Sardoura (Silva et alii, 1996: 99). Por este castro deve ter passado (ou nele terá estacionado durante algum tempo) um destacamento da Legio X Gemina, no reinado de Cláudio (AlarCão, 2004b).

$\mathrm{O}$ vale do rio Paiva, pelo menos até Meitriz (se não até qualquer ponto mais a montante), integraria também o território dos Paesuri. A sul, seria este limitado pelo maciço montanhoso que os documentos medievais chamam mons Fuste e no qual hoje distinguimos as serras de S. Macário, Arada e Freita (CoElHo, 1977: 20).

À delimitação hipotética que acabámos de fazer pode opor-se um argumento: a área definida não tem unidade geográfica. Reflexo dessa diversidade é a sua divisão, no séc. XI, em diversos "territórios": Geronzo, Pavia, Varganense, Arauca e Penafidelis de Covas - para além de outros menores, designadamente um de Senabria que sugere um castro *Senabriga (MERÊA e GIRÃO, 1948). 
O território Geronzo ou Ieronzo abrangia a vertente setentrional da serra de Montemuro e as terras até ao Douro. O de Pavia integrava a bacia inferior do rio Paiva. O Varganense estendia-se ao longo da margem direita do mesmo rio. Podemos duvidar se o grafema $<\mathrm{g}>$ de Varganense não corresponde ao fonema /z/ e se, por conseguinte, Varganense não se pronunciaria Varzanense (ou Varzenense, de varzena). De qualquer forma, Varganense significava "território da várzea". Viterbo (1966: 625) regista varga como sinónimo de várzea ou veiga.

O território Arauca era delimitado pelas serras que na Idade Média se chamavam mons Fuste e serra Sicca. O mons Fuste, como dissemos, integrava as serras hoje de S. Macário, Arada e Freita. As actuais serras da Mó e do Gamarão correspondem à serra Sicca.

A integração da bacia do curso inferior do rio Paiva no território dos Paesuri parece confirmada por uma inscrição rupestre que se acha no lugar de Pindelo, na freguesia de Nespereira do concelho de Cinfães. A leitura do texto não suscita demasiadas dúvidas mas a sua interpretação é difícil. José d' Encarnação e Luís M. da Silva Pinho, que publicaram a inscrição (F.E., 66, n. ${ }^{\circ}$ 299), limitaram-se honestamente a dar "uma série de pistas" para o seu entendimento.

Cremos não desvirtuar o pensamento dos autores supondo que a leram desta forma:

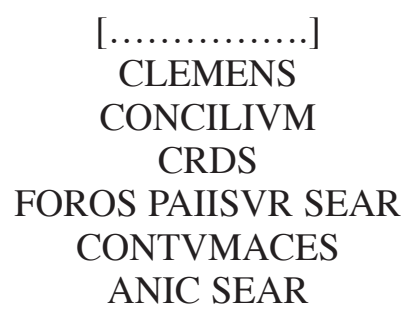

A fractura do penedo impede-nos a restituição da primeira linha. Apenas se vêem dela os pés de algumas letras, insuficientes para uma restituição. Podemos até perguntar-nos se não haveria mais linhas acima da primeira que é hoje inteiramente legível - isto é, aquela onde os autores leram Clemens. O desconhecimento do que terá desaparecido afecta, naturalmente, qualquer hipótese de interpretação.

A palavra concilium é perfeitamente legível. Alude-se aqui, possivelmente, a uma assembleia ou reunião de homens responsáveis por um governo local. 
O sistema político-administrativo introduzido pelos Romanos, com suas civitates, duúnviros, ordines, etc., não excluiria "administrações" locais em vici, castella ou pagi. Sabemos muito pouco destas administrações, particularmente no que concerne à província da Lusitânia. Imaginamos, porém, que, num castellum ou vicus, poderá ter havido algo semelhante a uma pequena assembleia ou conselho responsável pela administração local. Na ausência de edifício próprio, poderiam esses concilia reunir-se junto de uma fonte, de uma árvore mais velha ou mais frondosa, de uma fraga.

Na primeira linha legível da inscrição rupestre de Pindelo parece-nos que se vê olEMENS e não CLEMENS. Tratar-se-ia de um etnónimo, identificando o concilium. Teríamos, assim, Olemens(ium) concilium e uns *Olemenses que seriam os habitantes de um castellum *Olema. A verdade, porém, é que não encontramos registo de etnónimo ou topónimo semelhante nem, na microtoponímia local, nome que possa ter conservado memória do suposto antigo nome do lugar. *Olema, a ter-se conservado, e supondo que o nome era proparoxítono, poderia ter dado Uima. Mas este nome encontra-se hoje distante de Pindelo: Uima é nome de afluente do Douro que corre pelo concelho de Vila Nova de Gaia.

Na terceira linha, as letras C R D S poderão corresponder a iniciais de nomes ou palavras não substantivas. Talvez o $\mathrm{S}$ final esteja por $s$ (cripsit) ou $s$ (cripserunt). Em tal caso, C R D seriam iniciais dos nomes de quem escreveu. Recordaremos que, na famosa inscrição rupestre de Lamas de Moledo (Castro Daire) temos Rufinus et Tiro scripserunt (Curado, 2002: 73). Na de Freixo de Numão, CIL II 430, Ciri cur (averunt) (Tovar, 1985: 236). O verbo curare é diferente de scribere. Mas, num caso como noutro, o que importa assinalar é a identificação de quem fez (ou mandou fazer) as inscrições.

O sem-sentido das letras SEAR que surgem na $4 .{ }^{\mathrm{a}}$ linha e se repetem na 6. ${ }^{a}$ constitui uma das maiores dificuldades desta inscrição. As mesmas letras repetem-se em inscrições rupestres da serra do Caramulo (VAZ, 2001). Será que compõem palavra? Será que devemos ver nelas um etnónimo Sear $(i)$ ? Vista a sua repetição no penedo de Pindelo e nos rochedos da serra do Caramulo, não se tratará antes de fórmula jurídica que, por normalizada, podia ser abreviada? Não podemos interpretar as letras como (cum) s(ignis) e(pidicticalibus) a(gros) r(enormarunt) ou a(gris) r(enormatis)? A inscrição recordaria, pois, uma cadastração ou finium regundorum actio realizada com implantação de marcos. 
Admitindo (cum) s(ignis) e(pidicticalibus) a(gros) r(enormarunt), temos de procurar um sujeito para renormare. À primeira vista, esse sujeito poderia ser Paesur(i). Mas tal hipótese não deixa de suscitar dúvidas ou objecções.

Numa actio como a que aqui estará eventualmente registada esperaríamos, como sujeito, a ordo Paesurorum ou magistri ou duunviri dos Paesuri e não o etnónimo Paesur(i). Por outro lado, se o que foi objecto da suposta renormatio foram os a(gri), que faremos desse outro acusativo que precede o etnónimo, isto é, foros?

A leitura foros, aliás, não está isenta de dúvidas. Pela fotografia publicada em F.E., 66, n. ${ }^{\circ}$ 299, diríamos que deve ler-se VOROS, quer se trate de uma só palavra, quer se trate de duas: V poderia ser uma abreviatura e oros, outra palavra. Não deixa de ser estranha a maior dimensão do F ou V.

Admitindo foros, não se trata de forum, $-i$, visto que este nome em caso nenhum faz foros.

Foros surge-nos em Columela, R.R., 10, 91-93 com o sentido de "sulcos":

Tunc quoque trita solo splendentia sarculo sumat angustosque foros aduerso limite ducens, rursus in obliquum distinguat tramite paruo.

"Que ele agarre na enxada tornada resplendente pela fricção do solo, que trace sulcos estreitos perpendiculares ao caminho e que os corte, por seu turno, por um trilho secundário."

Se admitirmos foros como acusativo do plural de forus, - $i$, os Paesuri teriam traçado sulcos (ad) a (gros) r(enormandum). Mas esta nossa reinterpretação enfrenta uma dificuldade: os agros, tendo sido redefinidos por sulcos, não poderiam tê-lo sido ao mesmo tempo por $s$ (igna) e(pidicticalia).

A interpretação (per) foros Paesur(orum) (cum) s(ignis) e(pidicticalibus) a (gri) r(enormantur) - "Por determinação dos Pesuros, os campos são redefinidos por marcos" - parece dificilmente aceitável, ainda que não possa, talvez, ser liminarmente afastada, visto que forum agire significava exercer jurisdição ou decidir uma questão pendente. Não encontrámos forus, $-i$ com o sentido de decisão tomada por magistrados mas talvez tal sentido não deva excluir-se. 
A eventual leitura voros ou $v(\ldots)$ oros não resolve as dificuldades nem parece possível, pois vorus é palavra que não existe no latim e oros é acusativo de nome nenhum.

Podemos pensar que, tendo havido renormatio dos campos, tinha anteriormente sido feita uma divisão por meio de sulcos. Tal cadastração teria sido agora revista e os limites das terras teriam sido assinalados por marcos pétreos. A palavra foros não teria, nesta inscrição, o exacto sentido de "sulcos", mas o de "limites marcados por sulcos". Se entendermos, porém, foros Paesur(i) (cum) s(ignis) e(pidicticalibus) a(gris) r(enormatis), falta-nos a forma verbal, que seria r(enouarunt).

Na 5. ${ }^{a}$ linha, José d' Encarnação e Luís M. da Silva Pinho leram contumaces e relacionaram a palavra com a expressão adversus contumaces (contra os recalcitrantes) que se encontra numa carta, datada de 119 d.C., enviada por Cláudio Quartino aos duúnviros da cidade de Pamplona. A interpretação poderá ser aceitável e talvez mesmo a correcta. Contumax é, porém, adjectivo do qual se poderia ter formado um advérbio com o sentido de "firmemente". Os Paesuri teriam colocado marcos para serem respeitados sem contestação. A forma contumaciter seria a correcta, mas um erro gramatical (contumace em vez de contumaciter) não é inadmissível. Mas que faremos então do S com que termina a 5. linha, tanto mais que não é evidente um punctus distinguens? Dado que a fractura do rochedo não nos permite saber se o $\mathrm{S}$ seria a primeira letra de outra palavra, convém manter alguma reserva quanto à leitura contumaces, tanto mais que não é claro a que etnónimo se aplicaria o adjectivo: a Anic(enses)?

Na 5. ${ }^{\mathrm{a}}$ linha poderemos eventualmente ler ANIC(enses), supondo um etnónimo correspondente a um topónimo *Anicum ou ANIC(ienses), correspondendo a Anicium. É conhecido o topónimo Anicium.

Admitida esta hipotética reconstituição Anic(enses), as letras SEAR da última linha estariam por s(igna) e(pidicticalia) a(gros) r(enormandum), isto é, o $r(\ldots)$ corresponderia a uma forma do supino e não do perfeito de renormare. Também poderíamos desdobrar s(ignis) e(pidicticalibus) a (gris) r(enormatis). Mas, em qualquer caso, careceríamos de uma forma verbal que exprimisse a aceitação, por parte dos Anic(enses), da renormatio - ou o compromisso de respeitar o cadastro. Ora na inscrição de Pindelo vê-se que havia algumas letras mais a seguir a SEAR da última linha, ainda que, pela fotografia publicada, não possamos identificá-las. 
Voltando à 5. ${ }^{\mathrm{a}}$ linha, se lermos contumace em vez de contumaces e considerarmos que o $\mathrm{S}$ é inicial de outra palavra, poderemos supor um etnónimo S[..]ANIC(enses)?

Tal como José d' Encarnação e Luís M. da Silva Pinho, não conseguimos apresentar uma interpretação convincente da inscrição de Pindelo e limitamo-nos a propor "uma série de pistas", das quais a mais digna de consideração será, talvez, a de ver em SEAR não um etnónimo mas uma fórmula jurídica composta por quatro palavras que estarão abreviadas pelas suas iniciais. De qualquer forma, temos aqui, provavelmente, registo de uma cadastração. A população cujos campos terão sido objecto de renormatio poderá ter sido a do castro conhecido pelo nome de Crasto ou Castelo Velho da freguesia de Nespereira, em cujo aro fica o lugar de Pindelo? O castro acha-se identificado, ainda que não tenha sido objecto de escavações (PINHO, LiMA e CORREIA, 1998: 12). Talvez uma via secundária ligasse Espiunca à aldeia de Nespereira e daqui seguisse para S. Cristóvão de Nogueira e (ou) Cárquere.

$\mathrm{Na}$ área que definimos como possível território dos Paesuri podem identificar-se, a partir dos vestígios arqueológicos, alguns povoados aparentemente mais importantes.

O primeiro, partindo de Oriente para Ocidente, é o de Cárquere (Resende) - que temos proposto como capital de civitas, ainda que hoje se nos levantem dúvidas (ALARCÃO, 2000: 166).

De Cárquere procede um dos maiores conjuntos de inscrições funerárias romanas de Portugal (Dias, 1987; CARON, 1996b; SEQUEIRA e LOPES, 2000). Têm um estilo próprio que já foi salientado por diversos autores. Por vezes, apresentam toscas figuras humanas que representam os defuntos.

Se não podemos, dada a ausência de inscrições honoríficas ou de vestígios evidentes de edifícios públicos, deixar de ponderar as dúvidas expressas por L. CARON (1996c) quanto à capitalidade do lugar, mantemos pelo menos a ideia da importância da povoação na época romana. O achado, aí, de uma ara a Júpiter Óptimo Máximo, posta por uns castellani, poderia levar-nos a considerar Cárquere como um simples castellum, isto é, castro romanizado. Mas, como noutro lugar sugerimos (AlARCÃo, 2004b), estes castellani que consagraram a ara poderão corresponder a uma centúria da Legio X Gemina que, no tempo de Cláudio, terá estado, durante algum tempo, instalada em Cárquere ou nas imediações. 
Propusemos também, como nome de Cárquere, Tuentica (AlarCão, 2000: 166-167). Trata-se de uma "paróquia" suévica integrada no bispado de Lamego. Talvez o nome pré-romano e romano de Cárquere tenha sido, porém, *Karkaris, com uma raiz *kark ou kerk- com os sentidos, respectivamente, de "pedra" e "anel" (PrósPER, 2002: 364; FERREIRA, 2004). O nome e a importância do lugar teriam persistido na época do domínio muçulmano, se acaso lhe corresponde a Karkar dos tempos de Ibn Marwān (VelHo, 1981: 273-274; ManZano Moreno, 1991: 196-200; CATARINO, 1995-1997: 465). Ibn Marwān e um seu aliado, Sa'dūn al-Surumbāqī refugiaram-se em Karkar por volta de 875, depois de aquele ter sido expulso de Badajoz (que começara a fortificar) por al-Mundir, filho do emir Muhammad. Em Karkar, Ibn Marwān foi cercado por tropas cordovesas. Depois de ter sido derrotado, fugiu para a Gallaecia e aliou-se a Afonso III. A identificação desta Karkar com a Cárquere do concelho de Resende não deve considerar-se segura; mas não nos parece impossível, dado que o episódio precede o grande avanço que, no tempo de Afonso III, conduziu à ocupação de Lamego, Viseu e Coimbra. A cidade do Porto foi conquistada em 868; Chaves, em 872; Coimbra, em 879.

Por outro lado, não podemos deixar de perguntar-nos se Ibn Marwān terá fugido para tão longe. A referência à Gallaecia não ajuda à resolução da dúvida, pois o corónimo tinha então um sentido que ultrapassava, de longe, o da Gallaecia romana.

Talvez não seja inteiramente lendária a história que nos conta Duarte Galvão na sua Crónica de D. Afonso Henriques, cap. III:

Diz o cronista que Egas Moniz, logo que soube do nascimento do infante D. Afonso Henriques, veio a Guimarães e pediu ao conde D. Henrique, por mercê, que the confiasse o filho, para o criar. O conde, lastimoso, disse-lhe que o filho havia nascido tolhido das pernas; mas acabou por entregá-lo à guarda de Egas Moniz. A Virgem Maria apareceu então a este, num sonho, e disse-lhe que fosse a Cárquere e escavasse numa igreja que noutro tempo havia sido começada em sua honra e na qual acharia uma imagem sua; mais lhe disse que reconstruísse a igreja e o menino se curaria. Foi-se então Egas Moniz a Cárquere, mandou cavar e encontrou o templo e a imagem. Posta a criança sobre o altar, ficou curada das pernas. "E por causa deste milagre" - acrescenta o cronista - "foi depois feita nesta igreja, com muita devoção, o mosteiro de Cárquere”. 
É possível que tudo isto seja lenda, forjada pelos monges de Cárquere para atrair devotos e dádivas. Mas também poderá haver algum fundo de verdade nesta história. A igreja seria algum templo pagão romano ou cristão suevo-visigótico que se acharia arruinado nos finais do séc. XI ou nos inícios do XII?

Talvez de Cárquere tenha vindo o arquitecto que, na primeira metade do séc. XI, fez a igreja de Mosteiro de Fráguas (Tondela). $\mathrm{Na}$ inscrição que desta se conserva, infelizmente incompleta, lê-se: [...]RESSVS DE CARCERE FECIT (BARROCA, 1999: 135-137). O grafema $<\mathrm{C}>$ terá aqui o valor de /q/.

Voltando à época romana de Cárquere e ao elevado número de inscrições funerárias aí encontradas, claramente excepcional num castro romanizado, não deixaremos de observar, porém, que a onomástica é esmagadoramente de raiz indígena e que os gentilícios romanos são raros. Entre estes, contam-se os Iulii e os Valerii. Aliás, uma Iulia Fuscilla surge como dedicante a um M. Valerius Reburrus, seu sogro e, noutra lápide, como dedicada (CORREIA, 1972: 263). Mas Iulii e Valerii são gentilícios demasiadamente comuns para, destas lápides, podermos retirar conclusões significativas.

O nome indígena Pisirus tem sido relacionado com o etnónimo Paesuri (SıLVA, 1986: 282), mas a distribuição geográfica do antropónimo não permite sustentar tal relação (ou, pelo menos, deduzir da ocorrência do nome, a localização do "povo").

Outro lugar importante do suposto território dos Paesuri terá sido o de S. Paio, na freguesia de S. Cristóvão de Nogueira (Cinfães). Os seus vestígios monumentais talvez não tenham tido, até agora, a atenção que merecem (AnÓnimo, 1903; CoRTEZ, 1948: 77; PinHo, Lima e CorreiA, 1998: 16-17). Dentre esses vestígios, o mais notável é uma inscrição a Augusto (EE, IX: 102, n. ${ }^{\circ}$ 269; CARDOZO, 1972: 65, n. ${ }^{\circ} 73$ ).

\section{IMP(eratori) AVGVSTO DIVI/F(ilio) SACRVM PVBLICE/[..........]VLIVS}

Não parece que tenha havido mais nenhuma linha. Na terceira e última deveria ler-se, pois, o nome de quem, em representação de uma colectividade (todavia não identificada), tratou da homenagem pública. A forma verbal egit parece mais adequada que dedit ou dedicavit, exactamente por se tratar de um dedicante que não prestou homenagem pes- 
soal ao imperador, mas actuou em nome de uma comunidade. Um praenomen e a filiação antecederiam o gentilício [I]VLIVS. Atenta a data, não é inviável a ausência de cognomen. Assim, teríamos, na terceira linha, EGIT + praenomen + nome do pai + F(ilius $)$ + IVLIVS.

As grandes dimensões do bloco, com 1,44 m de comprimento e 0,53 de altura, sugerem a sua inserção num qualquer monumento.

Em S. Paio acharam-se outras inscrições. Uma, infelizmente, estava fragmentada e em demasia incompleta para se poder facilmente reconstituí-la (EE, IX: 102, n. ${ }^{\circ}$ 270; CARDOSO, 1972: 86, n. $\left.{ }^{\circ} 44\right)$. Outra, funerária, foi consagrada a um Flauus, filho de Pissirus (PINHO e PEREIRA, 1996a).

Ainda no concelho de Cinfães, o sítio de Passos (Tarouquela) tem proporcionado achados relevantes e, entre eles, uma ara a Júpiter Óptimo Máximo (GARCIA, 1991: 395, n. $\left.{ }^{\circ} 313 a\right)$. Os vestígios têm sido interpretados como os de uma villa (AlmeidA, 1993). A identificação poderá ser correcta. Mas não deixa de merecer atenção a referência a um "corredor" com quase dois metros de altura e no qual foram encontrados três capitéis e dois fustes de coluna (PINHO e PereIRA, 1996b). O suposto corredor seria pórtico? Não pode deixar de observar-se que os módulos dos elementos de colunas publicados por C. A. Brochado de Almeida (1993) são, pelas suas reduzidas dimensões, mais próprios de peristilo que de pórtico de edifício público monumental. Mas parecem consideráveis a área de dispersão de estruturas e materiais arqueológicos (alguns deles, do séc. I d.C. e importados da Bética e da Itália) e "a quantidade de colunas e capitéis provenientes de áreas distintas da aldeia" (PINHO, Lima e CORREIA, 1998: 18). Tais vestígios levaram os três autores citados a sugerirem a hipótese de o sítio de Passos corresponder a um vicus.

Na mesma freguesia de Tarouquela achou-se uma inscrição rupestre supostamente consagrada a uma divindade Mirobieus. Quem a fez (ou mandou fazer) identifica-se como [ ] apiobice(n)sis. O desaparecimento da(s) primeira(s) letra(s) do etnónimo ainda não tornou possível a restituição inequívoca do nome da civitas ou lugar (VILlaR, 2000: 129-130).

É possível que, na área de Castelo de Paiva, se venha a descobrir ainda algum aglomerado urbano importante. Mas, por enquanto, não há notícias dele. As referências a mosaicos que terão sido encontrados em Felgueiras, Vegide e Fundões (AlARCÃO, 1988, estações 3/23 a 3/25) não são insuspeitas. Talvez as referências a Felgueiras e Vegide se re- 
portem, afinal, a uma mesma estação, diversamente designada e situável na freguesia de Sobrado (SILVA, 1994: 103). As informações sobre necrópoles estão também, por vezes, afectadas por dúvidas quanto à sua exacta localização (SILVA, 1994: 117). Mas no concelho de Castelo de Paiva localizam-se as de Folgoso, Valbeirô, Campo da Torre, Vales, Valdemides e Paulinhos (Silva, 2003: 12).

Na margem do rio Paiva, perto da sua confluência com o Douro, havia uma inscrição rupestre, CIL II 6211, que Hübner interpretou como miliário mas que seria, mais provavelmente, honorífica, consagrada ao imperador Adriano.

Partindo dos dados arqueológicos conhecidos, os povoados mais importantes na época romana, imediatamente a sul do Douro e a ocidente de Lamego, parecem ser, pois, de oriente para ocidente: Cárquere, S. Paio, Passos, Monte Murado. Os três primeiros pertenceriam aos Paesuri; Monte Murado, aos Turduli Veteres. Poderá ter havido, repetimos, outro aglomerado na área de Castelo de Paiva. Outras estações arqueológicas do concelho de Cinfães (PinHo, 1997; PinHo, LiMA e CORREIA, 1998) não parecem merecer particular atenção neste nosso esforço de identificarmos os lugares principais - ainda que escavações em alguns deles possam vir a revelar que um ou outro teve, afinal, na época romana, uma relevância de que os achados arqueológicos superficiais não permitem suspeitar.

Por outro lado, lendo Ptolemeu, II, 5, 6, acharemos que o geógrafo menciona três poleis que poderão ter ficado situadas na margem esquerda do Douro, e não muito distantes do rio, entre Lamego e Vila Nova de Gaia. São elas: Lauare, Aritium e Araducca. Quanto a esta última, alguns manuscritos da Geografia de Ptolemeu registam Araducta e não é fácil decidir qual a forma mais correcta, visto que nenhuma delas se encontra confirmada por qualquer outra fonte.

É certo que as coordenadas ptolemaicas não merecem muita confiança, quer por erros de cálculo do geógrafo e/ou das suas fontes, quer por erros de cópia que se podem ter acumulado através da tradição manuscrita. Não havendo, porém, prova em contrário, admitiremos como possível a localização, na referida faixa, daquelas três poleis que Ptolemeu situa na Lusitânia e, portanto, a sul do Douro. Mas não conseguimos equacionar, com um mínimo de credibilidade, aquelas poleis com os aglomerados identificados através dos vestígios arqueológicos.

Partindo do Parochiale suévico dos fins do séc. VI (DAVID, 1947) e admitindo, por um lado, que a diocese de Lamego viria até ao rio Arda 
e, por outro, que a lista das "paróquias" daquela sede está organizada no sentido contrário ao dos ponteiros do relógio (mas ambas as ideias são meros pressupostos e não evidências), teríamos, a ocidente de Lamego e até àquele rio, Tuentica e Arauoca. Mais uma vez, porém, não conseguimos equacionar os nomes do Parochiale com os povoados arqueologicamente comprovados: Tuentica, por exemplo, coincidirá com Cárquere (como sustentámos em AlARCÃo, 2001: 47), com S. Paio ou com Passos?

É possível (ou mesmo provável) que a Araducca de Ptolemeu se deva identificar com a Arauoca suévica, visto ser muito credível a evolução Araducca > Arauoca. Na continuada evolução da língua, o nome da terra teria dado Arauca, que se encontra pela primeira vez atestado no documento PMH, DC., n. ${ }^{\circ}$ 63, de 951. O nome de Arouca - o da vila hoje conhecida sobretudo pelo seu famoso convento - deriva, obviamente, de Arauca. Não podemos, porém, situar a Araducca ptolemaica em Arouca e dificilmente se pode sustentar a localização da Arauoca suévica no sítio que a actual vila de Arouca ocupa.

As origens da vila de Arouca e do seu famoso mosteiro de S. Pedro, apesar de tratadas por vários autores (entre eles, FERnANDES, 1964 e 1965 e COELHO, 1977), continuam imprecisas. Tentaremos articular as fontes documentais com os poucos dados arqueológicos conhecidos - dados que se encontram reunidos por António Manuel S. P. Silva (2004). O que contaremos deve, porém, considerar-se mera hipótese de reconstituição da história antiga e alto-medieval do concelho - hipótese que novos dados arqueológicos poderão desmentir (ou confirmar).

Tudo quanto, na época romana, se recolheu até agora em Arouca é um modesto "tesouro" de 20 moedas, das quais a mais recente terá sido cunhada entre 378 e 383 d.C. Um outro tesouro, bem maior, foi encontrado próximo do lugar de Reguengo, na freguesia de Urrô. Compunham-no pelo menos 3047 moedas, com predomínio das do segundo quartel e meados do séc. IV d.C.

As moedas poderão ter circulado ainda no séc. V d.C. - embora, para o tesouro de Reguengo, tenhamos de aguardar a sua publicação antes de nos podermos pronunciar em definitivo. Mais incerta que a cronologia dos ocultamentos é, porém, a natureza das estações arqueológicas que eles indiciam, visto não haver, nesses lugares, quaisquer outros vestígios conhecidos. O tesouro de Arouca, pela sua modéstia, poderia 
ter sido ocultado num simples casal. O de Reguengo, mais importante, não tem de ser tomado como indício de uma villa. Poderia corresponder a uma granja ou, se acaso passasse por Urrô alguma via, a uma mutatio ou mansio. Mas só outros achados poderão resolver as nossas dúvidas.

Na mesma época, isto é, nos fins do séc. IV ou nos inícios do $\mathrm{V}$ d.C., existiriam, como aglomerados populacionais de alguma dimensão, o de Alvariça (Espiunca) e o de S. João de Valinhas.

O primeiro está atestado apenas pela sua necrópole (SILVA, 2003). Aí se recolheram sete estelas epigrafadas e uma anepígrafa, bem como dezenas de peças cerâmicas e moedas. Vasos e numismas acham-se hoje descontextualizados e perdidos ou dispersos por várias instituições ou particulares. O texto das inscrições, encabeçado pela fórmula $\mathrm{D}(i s)$ $\mathrm{M}$ (anibus) S(acrum), mostra que a população ainda se não achava cristianizada. Os materiais cerâmicos que se recolheram nas sepulturas (ou em algumas delas) falam no mesmo sentido, ainda que não de modo inequívoco. Não pode deixar de dar-se atenção à notícia (todavia não confirmada) da existência de uma outra necrópole a algumas centenas de metros da primeira. Em tal caso, poderíamos ter um povoado de alguma dimensão, com um cemitério num dos extremos e outro no extremo oposto, ao longo de uma eventual via romana que atravessaria o lugar. A verdade, porém, é que não há vestígios confirmados desse hipotético povoado.

O nome da aldeia de Espiunca, em cuja freguesia se situa a necrópole, deriva, certamente, de spelunca, com o sentido de "cova". Tal nome poderia dar-se a celas eremíticas cavadas na rocha, similares às que se encontram nos vales do rio Bestança e do ribeiro Sampaio, no concelho de Cinfães (PINHO, 1997: 41-43), bem como noutros lugares. Mas não temos conhecimento de que se achem em Espiunca.

$\mathrm{O}$ castro de S. João de Valinhas (na freguesia de Santa Eulália), instalado no Bronze Final mas com ocupação romana, poderá ter sido importante no séc. VI d.C., atentas as cerâmicas que se recolheram e podem (ou devem) atribuir-se a esse período.

Nos inícios do séc. IX, o castro de S. João de Valinhas mantinha-se ocupado - e talvez até com renovada importância. Terá sido aí instalado um castelo roqueiro que, reconstruído, terá permanecido até aos fins do séc. XII ou aos inícios do XIII (SILVA e RIBEIRO, 1999).

Se, aparentemente, a área de Arouca não foi muito habitada na época romana, a situação seria diferente no séc. $\mathrm{X}$, pois um documento 
de 972 (Coelho, 1977: 187, doc II) alude a multi boni homines qui sunt in valle Arauca. Seria importante, já nos inícios do século, o povoado de Moldes, documentado, com sua igreja, a partir de 925 (PMH, DC., n. ${ }^{\circ}$ 746). Mais precisamente, o documento alude à igreja de Sancta Maria de ribulo Mollides - e a consagração a Santa Maria deixa-nos suspeitar de uma igreja com funções "paroquiais". Refere ainda esse documento que post multis annis (e o post reporta-se a 925) venerunt Sarraceni. Cecidit ipso territorio in herematione et fuit ipse ecclesia destructa. A igreja foi depois restaurada mas voltou a ser abandonada em 975. Em 1001 foi reocupada e consagrada a Santo Estêvão. Todas estas informações se encontram no citado diploma. Devemos deduzir um ataque muçulmano entre 925 e 975 . Ou talvez dois: um primeiro, anos depois de 925; mas, reconstruído o templo, um segundo ataque, ocorrido em 975, levou de novo ao abandono da igreja que só em 1001 terá sido reocupada.

No mesmo séc. X existiriam as aldeias de S. Pedro, Romariz, Castro, Cartimir (e, possivelmente, outras mais). A de Cartimir desapareceu (ou mudou de nome) mas as outras três mantêm-se com os mesmos topónimos.

Relativamente ao mosteiro de Arouca, o que nos importa no documento . $^{\circ} 746$ dos PMH, DC. é que os frades do convento arouquense reclamavam a metade da igreja de Moldes, alegando que essa parte lhes teria sido doada em 925. A ser assim, a fundação do mosteiro de Arouca seria anterior a essa data.

O mosteiro terá sido fundado, entre 915 e 925 , por Loderigo e Vandilo. Posteriormente, mas antes de 951, foi adquirido por Ansur Godesteiz e sua mulher Eileua, que o terão ampliado ou reconstruído. Tem sido mesmo posta a hipótese de o primeiro mosteiro ter ficado, não no lugar da actual vila de Arouca, mas no sítio da aldeia de S. Pedro, que fica a menos de $1000 \mathrm{~m}$ do convento da vila. Ansur e Eileua teriam transferido o mosteiro do seu primitivo lugar para o chão onde hoje vemos o convento que foi uma das principais casas monásticas portuguesas.

Os documentos mais antigos referentes ao mosteiro têm sido objecto de leitura atenta de vários autores (particularmente de FERNANDES, 1964 e 1965; vid. também CoELHo, 1977). A sua interpretação não se afigura fácil, até (ou sobretudo) porque o termo villa, nos documentos da Reconquista, é muito equívoco.

$\mathrm{O}$ termo villa tanto designava uma herdade como uma aldeia. Podemos, assim, distinguir villa-herdade, de villa-aldeia - mas nem 
sempre é fácil determinar, a partir dos documentos, o que é que o termo, neste ou naquele caso concreto, designava. Aliás, herdade e aldeia não eram realidades que mutuamente se excluíssem, pois um proprietário podia ter uma herdade de grande ou média dimensão e os que nela trabalhavam, como criados ou arrendatários de parcelas, podiam viver concentrados, eventualmente em torno do "paço" do senhor, formando um aldeia de poucos fogos. Numa grande herdade podia até haver várias pequenas aldeias (eventualmente designadas pelo termo vilares).

No caso de villa-herdade inicialmente de um único proprietário, podia vir a ser dividida por heranças e partilhas ou parcialmente vendida a outro(s) sem que o nome da villa se perdesse. Mas a cada uma (ou a algumas) das parcelas podia dar-se também o nome de villa. Assim, formar-se-iam várias villas, cada uma com o seu nome próprio, no interior de uma villa cujo nome primitivo se mantinha quando já não correspondia a propriedade de um único senhor. O nome da villa inicial tornava-se, assim, um corónimo, isto é, nome de região ou área na qual se integravam outras villas. Nalguns casos, o nome de uma villa que era corónimo poderia ter outra origem. Se villa Arauca foi corónimo, o nome terá derivado do da antiga paróquia suévica Araducca.

Talvez, num ou noutro caso, a villa correspondesse ao que hoje designamos por paróquia ou freguesia. No séc. X (e ainda posteriormente), as igrejas "paroquiais" e as "paróquias" resultavam muitas vezes de iniciativa privada de senhores laicos, de mosteiros ou presbíteros, com reduzido (ou nenhum) controlo por parte dos bispos - os quais, aliás, nos tempos conturbados da Reconquista, nem sempre residiam nas suas dioceses.

Relendo os documentos do séc. X à luz do que acabámos de dizer, parece-nos que haveria, no início do mesmo século, uma villa Sancti Petri que seria villa-herdade. Nela haveria uma aldeia, no lugar que a actual aldeia de S. Pedro ocupa. Nessa aldeia teria sido erguida uma igreja (com funções paroquiais?) e, do nome do Apóstolo, teria a herdade tomado seu próprio nome. Noutro lugar da mesma herdade ou em herdade contígua terão Loderigo e Vandilo instalado um mosteiro consagrado a S. João Baptista (ou a S. Pedro?) e aos SS. Cosme e Damião. O cenóbio poderá ter sido edificado no lugar onde hoje se encontra, isto é, no sítio da actual vila de Arouca.

Antes de 951, Ansur Godesteiz e Eileua, proprietários da villa Sancti Petri, construíram uma igreja dedicada a S. Pedro, S. Paulo e aos SS. Cosme e Damião. É incerto se esta igreja foi uma reconstrução da 
anterior de S. Pedro (no lugar da actual aldeia do mesmo nome) ou uma fundação inteiramente nova, no lugar onde se erguia o mosteiro. Seja como for, Ansur e Eileua construíram a igreja pro remedio animas suas pro ad monacos et fratribus et sororibus habitantibus (PMH, DC., n. $\left.{ }^{\circ} 423\right)$. Independente de qualquer oratório ou pequeno templo que o mosteiro tivesse para serviço próprio dos seus monges e suas freiras (pois o mosteiro era dúplice), esta igreja foi doada pelos ditos Ansur e Eileua ao mosteiro de S. João Baptista e dos SS. Cosme e Damião. Ao mesmo tempo que doavam a igreja, Ansur e Eileua fizeram doação, ao mosteiro, da própria villa Sancti Petri, que era sua propriedade (PMH, DC., n. ${ }^{\circ}$ 63).

Em data incerta, mas ainda por volta de 951, Ansur e Eileua terão reconstruído ou ampliado o próprio mosteiro (PMH, DC., n. $\left.{ }^{\circ} 781\right)$ que, em 956, continuava a ter, por padroeiros, S. João Baptista e os SS. Cosme e Damião (CoElho, 1977: 186, doc. I). A questão dos oragos, é, porém, difícil de apurar (CoELHo, 1977: 25-26).

Mas o que mais nos interessa não é o problemas dos santos padroeiros ou o da origem do mosteiro mas o da localização da Arauoca suévica (identificável com a Araducca ptolemaica?), cujo nome, mais do que provavelmente, se encontra na origem do da villa Arauca dos documentos dos séculos X e XI.

A. de Almeida Fernandes sustentou que, na Alta Idade Média, Arauca foi nome de "território" antes de ser nome de povoação. Disse o autor que "ainda nos inícios nacionais não aparece Arouca como nome de um lugar determinado, mas como simples designação do vale do Arda superior e do de Moldes" (Fernandes, 1964: 119). Para Almeida Fernandes, o nome do território medieval de Arouca terá derivado do da antiga "paróquia" suévica Arauoca, que ficaria localizada no morro conhecido pelo nome de Cividade ou Muro, sobre o rio Arda, na extrema das actuais freguesias de Roças e Urrô (FERNANDES, 1964: 123, 181, 189).

A derivação Araducca $>$ Arauoca $>$ Arouca não suscita dúvidas. Mas a questão linguística é diferente da localização da polis ptolemaica Araducca e da "paróquia" suévica Arauoca. Ora tudo quanto do morro do Muro se conhece são vestígios, aliás pouco abundantes, de ocupação da Idade do Bronze: o sítio não terá tido ocupação romana ou suévica (SILVA, 2004: 215-216 e 250-251).

A falta de vestígios arqueológicos destas duas épocas no morro da Cividade ou do Muro levaram Filomeno Silva (1999: 26) e António 
M. C. Lima (in SILVA, 2004: 318) a contestar a opinião de A. de Almeida Fernandes e a identificar a Arauoca suévica com o castro de S. João de Valinhas onde, como atrás vimos, se encontram materiais arqueológicos passíveis de datação no séc. VI d.C. Este seria o castro Arauca de vários documentos datados de 1080 pelo menos até 1101 (recolhidos por FERNANDES, 1964: 185).

A. de Almeida Fernandes (1964: 170) considerou, porém, essa possibilidade de o castro Arauca ser o de S. João de Valinhas. A nosso ver justificadamente, afastou tal hipótese, visto que as referências toponímicas e corográficas contidas nos documentos que aludem ao castro Arauca apontam para o morro da Cividade ou do Muro.

Levanta-se-nos, assim, um problema: como poderia chamar-se, nos séculos XI e XII, castro Arauca a um lugar que não pode, de modo nenhum, ter sido a Arauoca suévica nem a Araducca ptolemaica?

A resposta poderá ser esta: no século XI, quando o Parochiale suévico era um texto sobejamente conhecido (e invocado pelos bispos nos seus esforços de reorganização das dioceses), sabia-se que tinha havido uma "paróquia" da diocese de Lamego chamada Arauoca, mas já não havia memória da sua localização exacta. Conhecidos os vestígios de uma ocupação muito antiga no morro do Muro (e tais vestígios seriam, no séc. XI, talvez muito mais evidentes do que hoje), ter-se-á imaginado ou suposto que esse era o lugar da antiga Arauoca.

Se pensarmos nos inúmeros casos em que certas populações, ainda hoje, acreditam que suas aldeias tiveram assento num morro próximo do qual não há vestígios arqueológicos ou os há pouco significativos e dizem que os habitantes foram, em tempos muito recuados, obrigados a abandonarem o lugar primitivo devido a uma invasão de formigas ou epidemia, admitiremos mais facilmente esta hipótese de os habitantes do vale do Arda terem localizado a antiga Arauoca num sítio onde ela, de facto, nunca esteve. No caso concreto de Arouca, podemos duvidar se a "lenda" teve origem popular ou erudita, isto é, se não terá sido antes inventada por boni homines que assim reivindicariam "pergaminhos" ou "uma genealogia" para a sua região.

Se, nos fins do séc. XI, se localizava (erradamente) a antiga Arauoca suévica no morro da Cividade ou do Muro, isso não significa, porém, que, nessa data, se ignorava o lugar onde tal "paróquia" suévica tinha realmente existido?

A nossa hipótese parece, à primeira vista, aceitável. Mas nós mesmos temos, contra ela, objecções. 
Não é inimaginável que, existindo Arauoca nos finais do séc. VI d.C. (data do Parochiale suévico), a povoação tenha sido abandonada no séc. VII ou VIII e que, nos finais do séc. XI, se tivesse perdido memória do seu exacto lugar. Mas, como a memória dos povos é geralmente longa, também nos podemos perguntar se, em três ou quatro séculos, se teria esquecido a posição do lugar. Por outro lado, e ainda que não tenhamos atestação documental do nome de castro Arauca para o morro do Muro antes de finais do séc. XI, os documentos comprovam que a área de Arouca era chamada villa Arauca já nos meados do séc. IX ou que valle Arauca era então o nome que se dava à área da moderna vila de Arouca. Não significa isso que o nome de castro Arauca era já dado nos meados do séc. X ao morro da Cividade ou do Muro? Ora, mesmo que a antiga Arauoca tivesse sido abandonada no séc. VII, estaria já perdida, nos meados do X, a memória do lugar?

Noutro trabalho (AlARCão, 2001: 47-48) sugerimos a possibilidade de Arauoca corresponder a Espiunca. Aí, porém, não se conhece senão uma necrópole, no preciso lugar de Alvariça. Vimos atrás que pode ter existido, nesse sítio, um povoado - ao qual pertenceria uma segunda necrópole todavia não confirmada. A verdade é que não se conhecem vestígios arqueológicos desse suposto e hipotético povoado. Admitindo, apesar de tudo (e como hipótese), a localização aí da Arauoca suévica, e mesmo no caso de a povoação ter sido abandonada no séc. VII ou VIII, não existiriam vestígios dela nos finais do séc. XI? E não seriam esses vestígios suficientemente importantes para que se mantivesse ainda viva a memória da antiga Arauoca? Recordaremos que, em 1078, o bispo de Braga, socorrendo-se do Parochiale suévico para sustentar os seus direitos à posse de uma outra "paróquia" suévica, a de Cotis, falava das ruínas visíveis das antigas "paróquias" de Equisis e Vergantia (CosTA, 1959: 379-380). Estes lugares estariam também abandonados nos finais do séc. XI mas não se tinha perdido memória desses sítios.

As dúvidas permanecem, pois, quanto à localização da Araducca ptolemaica e da Arauoca suévica. São apenas hipóteses as ideias de que as duas localidades correspondem a uma mesma povoação e que esta ficava no antigo território dos Paesuri. Não nos parece, porém, que estas hipóteses devam ser aposentadas sem termos outras que prestem melhor serviço. $\mathrm{O}$ mesmo diremos da localização que aqui propomos 
para os Paesuri, na sequência de trabalhos nossos anteriores, mas agora de forma mais circunstanciada. Confessamos, porém, não conhecermos os lugares por os termos directamente visitado: apenas pelo que deles tem sido escrito ou relatado. Outros arqueólogos, a quem os lugares e a paisagem sejam mais familiares, poderão, com sua directa experiência, apresentar outras propostas mais credíveis. Enquanto se não encontrarem escritos em pedra os nomes dos povoados, muitas dúvidas, porém, permanecerão. Talvez só o acaso de algum achado epigráfico possa decidi-las. Algumas colunas caídas e algumas pedras lavradas que não tenham sido até agora vistas, mas que aí permaneçam entre silvas ou carvalhos, poderão dar indício de outras povoações para além daquelas que assinalámos. De muitas que foram importantes, por esse todo país, etiam periere ruinae, até as ruínas desapareceram - ou, pelo menos, são hoje pouco visíveis. Talvez haja, no território dos Paesuri, lugares importantes ainda por descobrir.

P.S. - Numa conferência proferida em Arouca, em 25.06.2005, o Prof. Armando Coelho, sem ter proposto leitura da inscrição de Pindelo, sustentou que se trata de um texto condenatório de heresia e que PAIISUR $(i)$ é leitura errónea. Aguardaremos que o Prof. Armando Coelho publique a sua interpretação. De qualquer forma, não foi nesta inscrição que baseámos a nossa proposta de localização dos Paesuri. Nela apenas vimos uma confirmação da nossa hipótese.

\section{REFERÊNCIAS}

AlARCÃo, Jorge de (1988) - Roman Portugal. Warminster.

AlarCão, Jorge de (2000): Os nomes de algumas povoações romanas da parte portuguesa da Lusitânia, in Gorges, J.-G e Nogales Basarrate, T. (coord.) Sociedade y cultura en Lusitania romana, Mérida: 165-172.

AlARCÃO, Jorge de (2001) - As paróquias suévicas do território actualmente português.

In F. VILlAR e M. P. FERNÁNDEZ ÁlVAREZ (eds.), Religión, lengua y cultura prerromanas de Hispania. Salamanca, p. 29-59.

AlarCão, Jorge de, (2004a) - Notas de arqueologia, epigrafia e toponímia. I. Revista Portuguesa de Arqueologia, 7(1): 317-342.

AlARCÃo, Jorge de (2004b) -Destacamento(s) da Legião X Gémina no Baixo Douro no tempo de Cláudio?" Al-madan, 2. ${ }^{\text {a }}$ série, 13: 78-81.

AlmeIDA, C. A. Brochado de (1993) - A villa romana de Passos (Tarouquela - Cinfães). Revista da Faculdade de Letras do Porto. 2. ${ }^{a}$ série, 10: 433-450.

Almeida, C. A. Ferreira de e SAntos, Eugénio dos (1972) - O castro de Fiães. Revista da Faculdade de Letras do Porto. Série de História, 2: 147-168. 
Almeida, C. A. Ferreira de e Santos, Eugénio dos (1973) - O castro de Fiães, II. Revista da Faculdade de Letras do Porto. Série de História, 3: 207-214.

AlmeIDA, Fernando de (1953) - Terminus augustalis entre Talabriga e Langobriga. O Arqueólogo Português, 2. ${ }^{\mathrm{a}}$ série, 2: 209-212.

AnÓnImo (1903) - A freguesia de S. Christovam de Nogueira (concelho de Sinfães). O Arqueólogo Português, 8: 59-66.

Armstead, S. G. (1975) - Cuatro nuevas inscripciones romanas de Coria (provincia de Cáceres). Archivo Español de Arqueología, 48: 173-179.

BarrocA, Mário J. (1999) - Epigrafia medieval portuguesa (862-1422). Vol. II. Corpus epigráfico medieval português. tomo I. Lisboa.

CArdozo, Mário (1972) - Catálogo do Museu de Martins Sarmento. Secção de epigrafia latina e de escultura antiga. Guimarães.

CARON, Laurent (1996a) - Monuments épigraphiques de Cárquere. Ficheiro Epigráfico, 53 , n. ${ }^{\text {s }} 239-244$.

CARON, Laurent (1996b) - Art et société d'après les stèles funéraires de Cárquere. Conimbriga, 35: 69-106.

CARon, Laurent (1996c) - As estelas funerárias de Cárquere e o problema da localização da capital dos Paesuri. Al-madan, 2. ${ }^{\text {a }}$ série, 5: 5-6.

CATARINo, Helena (1995-1996) - Arqueologia do período islâmico em Portugal: breve perspectiva. O Arqueólogo Português, 4. ${ }^{a}$ série, 13-15: 457-484.

CinTrA, Luís F. Lindley (1961) - Crónica Geral de Espanha de 1344 (edição crítica do texto português). Lisboa.

Coelho, Maria Helena da Cruz (1977) - O mosteiro de Arouca do século X ao século XIII. Coimbra.

Colmenero, António Rodríguez (1993) - Corpus-Catálogo de inscripciones rupestres de época romana del cuadrante noroeste de la Península Ibérica. Corunha.

Correia, Vergílio (1972) - Obras, IV. Coimbra.

Cortez, F. Russel (1948) - A ara greco-romana do Castro de Fontes. Novos subsídios para o estudo dos cultos orientais na região do Douro. Anais do Instituto do Vinho do Porto, 9: 45-95.

Costa, Avelino de Jesus da (1959) - O bispo D. Pedro e a organização da diocese de Braga, vol. II. Coimbra.

Curado, Fernando Patrício (2002) - A "ideologia tripartida dos Indo-Europeus" e as religiões de tradição paleohispânica no Ocidente peninsular. In RIBEIRO, J. Cardim, Religiões da Lusitânia. Loquuntur saxa, Lisboa: 71-77.

David, P. (1947) - Études historiques sur la Galice et le Portugal du Ve au XIIe. Lisboa.

Dias, Lino A. Tavares (1993-1994) - Necrópoles no territorium de Tongobriga. Conimbriga, 32-33: 107-136.

DiAs, Lino A. Tavares (1997) - Tongobriga. Lisboa.

DiAs, Maria Manuela Alves (1987) - Antroponímia de Cárquere, Resende, Viseu (Lusitânia Portuguesa). Veleia, 2-3: 195-203.

DuARTE, Joaquim Correia (1994) - Resende e a sua história. Vol. I. O concelho. Resende. 
EnCARnAÇão, José d' e PINHO, Luís M. da Silva (2001) - Inscrição rupestre de Cinfães.

Ficheiro Epigráfico, 66, n. ${ }^{\circ} 299$.

FERnAndes, A. de Almeida (1964 e 1965) - Arouca na Idade Média pré-nacional. Arquivo do Distrito de Aveiro, 30: 28-69, 90-125, 168-205, 248-256; e 31: 41-68,

224-242 e 266-299. O artigo foi completado no vol. 32 (1966) da mesma revista.

FERnANDES, A. de Almeida (1999) - Toponímia portuguesa. Exame a um dicionário.

Arouca.

Fernandes, A. de Almeida e Silva, Filomeno (1995) - Toponímia arouquense. Arouca. FERrEIRA, Valentina G. (2004) - Personal and place-names with the Carc- form. In Boullón Agrelo (ed.), Novi te ex nomine. Estudos filolóxicos ofrecidos ao Prof. Dr. Dieter Kremer, Corunha: 187-196.

Galvão, Duarte (1918) - Cronica delrey Dom Affomso Hamriques (edição de Manuel de Castro Guimarães), Cascais.

Garcia, José Manuel (1991) - Religiões antigas de Portugal. Aditamentos e observações às "Religiões da Lusitânia” de J. Leite de Vasconcelos. Fontes epigráficas. Lisboa.

GuIMARÃES, Gonçalves (1987) - O povoamento medieval da terra de Arouca - Contributo para a elaboração da sua carta arqueológica. Actas das $1^{a s}$ Jornadas de História e Arqueologia do concelho de Arouca. Arouca: 59-76.

LE Roux, P. (1994) - Cités et territoires en Hispanie. L'épigraphie des limites. Mélanges de la Casa de Velázquez, 30(1): 37-51.

Mantas, Vasco Gil (1984) - A inscrição romana da estação luso-romana de Mogueira (Resende). Revista de Guimarães, 94: 361-370.

MANTAS, Vasco Gil (1994) - A rede viária romana da faixa atlântica entre Lisboa e Braga. Coimbra. (tese de doutoramento, policopiada, apresentada à Faculdade de Letras de Coimbra).

MAnZANo Moreno, E. (1991) - La frontera de Al-andaluz en época de los Omeyas, Madrid. MERÊA, Paulo e GIRÃO, Amorim (1948) - Territórios portugueses no séc. XI, Coimbra (reedição corrigida e aumentada do artigo publicado na Revista Portuguesa de História, II, 1943).

PInHo, Luís M. Silva (1997) - Património arqueológico do vale do Bestança, Cinfães. Pinho, Luís M. Silva e PereirA, António da Silva (1996a) - Estela funerária de S. Paio Cinfães), Ficheiro Epigráfico, 52, n. ${ }^{\circ} 236$.

Pinho, Luís M. Silva e Pereira, António da Silva (1996b) - Duas árulas de Passos (Cinfães), Ficheiro Epigráfico, 53, n. os 245-246.

Pinho, Luís M. Silva; Lima, António Manuel C.; CorReia, Alexandre Lourenço (1998) - Roteiro arqueológico de Cinfães. Cinfães.

PRÓSPER, Blanca María (2002) - Lenguas y religiones prerromanas del Occidente de la Península Ibérica, Salamanca.

SequeIrA, Carla e Lopes, A. Baptista (2000) - Inscriçõs romanas de Cárquere. O Arqueólogo Português, 4. ${ }^{\mathrm{a}}$ série, 18: 85-98.

Silva, António Manuel S. P. (1994) - Proto-história e romanização no Entre Douro e Vouga litoral. Elementos para uma avaliação crítica. Porto (tese de mestrado, policopiada, apresentada à Faculdade de Letras do Porto). 
SILva, António Manuel S. P. (2003) - A necrópole tardo-romana de Alvariça (Espiunca, Arouca). Algumas notas para uma revisão crítica, Arouca (= Cadernos do Centro de Arqueologia de Arouca, 2).

Silva, António Manuel S. P. (coord.) (2004) - Memórias da Terra. Património arqueológico do concelho de Arouca, Arouca.

Silva, António Manuel S. P. e Ribeiro, Manuela C. S. (1999) - A intervenção arqueológica em S. João de Valinhas (Arouca, Aveiro). Do povoado castrejo ao castelo da Terra de Arouca. In BARrocA, M. J. (coord.), Carlos Alberto Ferreira de Almeida. In memoriam, Porto, II: 363-374.

Silva, Armando Coelho F. da (1983) - As tesserae hospitales do castro da Senhora da Saúde ou Monte Murado (Pedroso, V. N. de Gaia), Gaya, 1: 9-26.

Silva, Armando Coelho F. da (1985) - Novos dados sobre a organização social castreja. In Actas del III Coloquio sobre Lenguas y Culturas Paleohispánicas, Salamanca: 201-204.

Silva, Armando Coelho F. da (1986) - A cultura castreja no Noroeste de Portugal, Paços de Ferreira.

SILva, Eduardo Jorge Lopes da et alii (1996) - Carta arqueológica do concelho de Castelo de Paiva, Porto.

Silva, Eduardo Jorge Lopes da e CunHA, Ana Leite da (1988-1994) - Inventário arqueológico do concelho de Cinfães: primeiros resultados. Gaya, 6: 325-340.

SILVA, Eduardo Jorge Lopes da e VAZ, João L. Inês (2001) - Novas inscrições rupestres do Castro da Mogueira (Cinfães). In Saxa Scripta. Actas do Simpósio Ibero-Itálico de Epigrafia Rupestre. Viseu: 75-78.

Silva, Filomeno (1999). Em redor do topónimo Arouca, Arouca.

Tovar, António (1985) - La inscripción del Cabeço das Fráguas y la lengua de los Lusitanos. In Actas del III Coloquio sobre Lenguas y Culturas Paleohispánicas. Salamanca: 227-253.

VAZ, João L. Inês (1979) - Término augustal de Goujoim (Armamar). Conimbriga, 18: 133-138.

VAZ, João L. Inês (1982) - Inscrições romanas de Balsemão (Lamego). Beira Alta, 41(1) 259-267.

VAZ, João L. Inês (1988-1994) - Epigrafia romana da Beira Douro - algumas notas. Gaya, 6: 137-154.

VAZ, João L. Inês (2001) - Mais uma inscrição rupestre da serra do Caramulo. In Saxa Scripta. Actas do Simpósio Ibero-Itálico de Epigrafia Rupestre, Viseu: 189-198.

VelHo, Martim (1981) - Ibn Marwān (Ibn al-Djilliki) e Sa'dūn al-Surumbāqī. A localização de Monsalude. Proceedings of the ninth Congress of the Union Européenne d'Arabisants et Islamisants. Leiden: 270-287.

VILlaR, Francisco (2000) - Indoeuropeos y no Indoeuropeos en la Hispania prerromana. Salamanca.

Viterbo, Frei Joaquim de Santa Rosa de (1966) - Elucidário das palavras, termos e frases... Vol. II, Porto. 


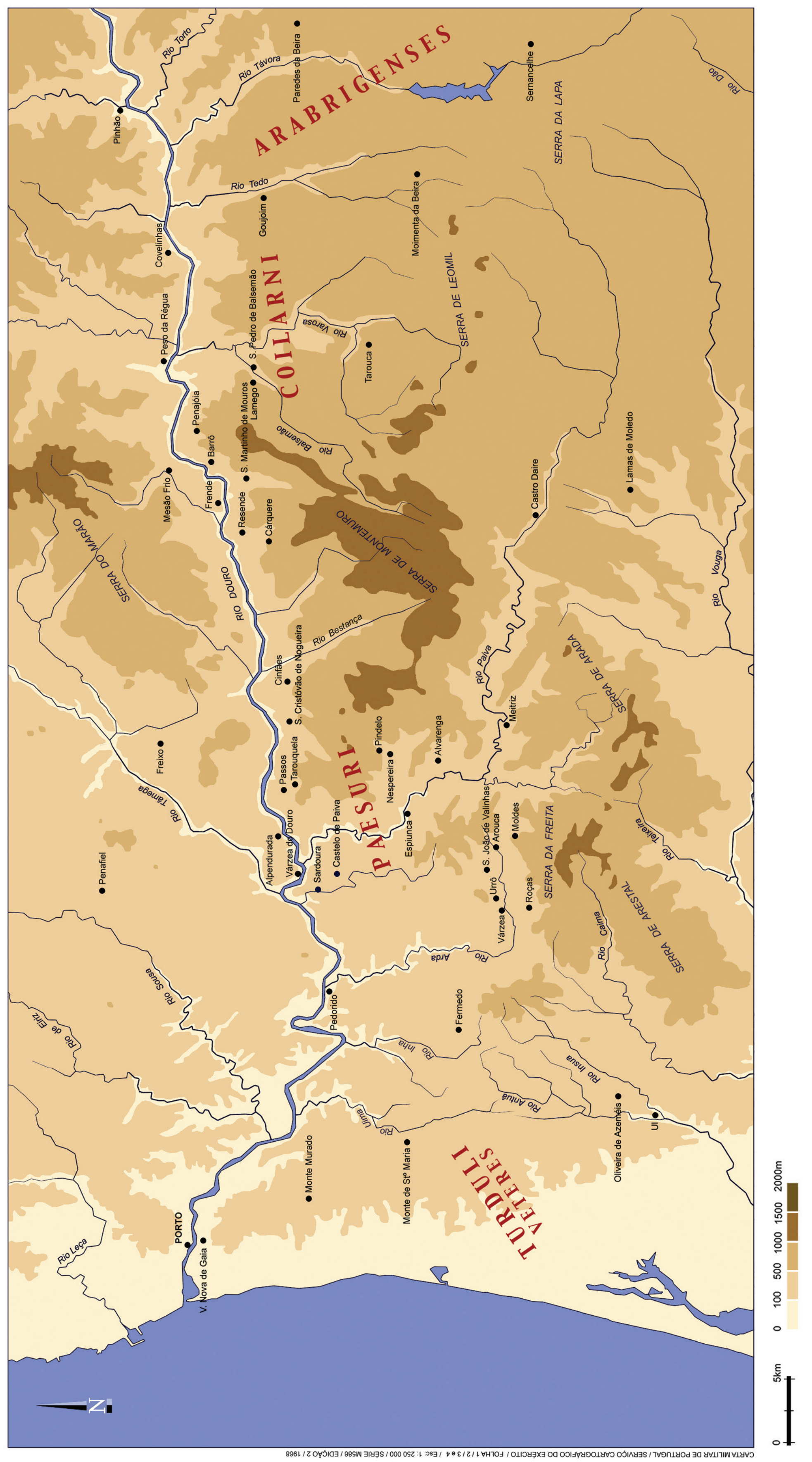

